\title{
Proceeding
}

Supplementary Issue: Autumn Conferences of Sports Science. Costa Blanca Sports Science Events, 18-19 December 2020. Alicante, Spain.

\section{Small-side games and size pitch in elite female soccer players: A short narrative review}

\author{
ITALO SANNICANDRO \\ University of Foggia, Italy
}

\begin{abstract}
Introduction: In recent years, in the soccer training have found widespread diffusion the games modified by rules, use of wildcard players, configuration field, players' number, size of the playing area, defined as smallsided games or SSG. Methodology: For the bibliographic search PubMed and Sport Discuss databases were used selecting articles published between 01/01/2016 and 01/12/2020. Two keyword groups were identified, using synonyms and similar terms, using the operator "OR":1) "small-sided games" OR "elite female soccer players" OR "field size" 2) "small-sided games" OR "elite female football players" OR "field size". Subsequently, all the categories were combined together using the "AND" operator. Results: The initial database search produced 77 results. After removing the duplicates (3), study on injury incidence (21), amateur soccer players (3), endocrine and biomechanical aspects (20), assessment preventive issue (12) and other aspects not related to performances (15), three studies were selected, analysed, and included in the narrative review. Discussion and conclusions: The physiological responses of female soccer players during SSGs have only been investigated relative to the players' number. The field size is considered a key factor in soccer training because the players' density conditions internal and external load. The studies analysed suggest that the most suitable format for achieving a high intensity of exercise with female soccer players, is precisely the medium filed size, that is, in the case observed for $4 \mathrm{vs} 4$, a size equal to $24.5 \mathrm{~m} \mathrm{x}$ $24.5 \mathrm{~m}$. The load control of specific sport exercises is useful for the injury's prevention and for relevant training organization to respond to the competitions' demands.
\end{abstract}

Keywords: Small-sided games; Female soccer players; Pitch size.

Cite this article as:

Sannicandro, I. (2021). Small-side games and size pitch in elite female soccer players: A short narrative review. Journal of Human Sport and Exercise, 16(2proc), S361-S369. doi:https://doi.org/10.14198/ihse.2021.16.Proc2.20

\footnotetext{
Corresponding author. University of Foggia, Italy.

E-mail: italo.sannicandro@unifg.it

Abstract submitted to: Autumn Conferences of Sports Science. Costa Blanca Sports Science Events, 18-19 December 2020. Alicante, Spain.

JOURNAL OF HUMAN SPORT \& EXERCISE ISSN 1988-5202

(c) Faculty of Education. University of Alicante

doi:10.14198/jhse.2021.16.Proc2.20
} 


\section{INTRODUCTION}

In team sports, the staff look for exercises that are more functional than the demands of the performance model (Sedano et al., 2009; Idrizovic, 2014; Ruiz-Esteban et al., 2020; Esposito \& Raiola, 2020; Elia et al., 2020; Di Domenico et al., 2019). This research is often directed towards ball exercises that can determine specific physiological adaptations (Aguiar et al., 2012; Clemente et al., 2012; Tan et al., 2012; Cronin et al., 2017; Giovanni et al., 2020; Esposito \& Raiola, 2020). In recent years, in the soccer training have found widespread diffusion the games modified by rules, use of wildcard players, configuration field, players' number, size of the playing area, defined as small-sided games or SSG (Aguiar et al., 2012; Castellano et al., 2013; Halouani et al., 2014; Sannicandro \& Cofano, 2018; Sannicandro, 2019; D'Isanto et al., 2019; Ceruso et al., 2019a).

These variations allow the athletes of the various open skill sports to be trained specifically (Tan et al., 2012; Raiola, 2014; Raiola, 2017; Raiola \& Altavilla, 2020; Ceruso et al., 2020; Ceruso et al., 2019b). In literature the advantages deriving from the use of SSG for performance are extensively described (Sampaio et al., 2007; Folgado et al., 2018; Coutinho et al., 2018a; Sannicandro, 2019): the coaches use the SSGs both with élite soccer players, and with young players (Casamichana et al., 2013 ; Castellano et al., 2013; Halouani et al., 2014; Leser et al., 2019; Sannicandro \& Cofano, 2018; Hill-Haas et al., 2009a; Hill-Haas et al., 2009b) because they optimize the training time (Halouani et al., 2017a; Halouani et al., 2017b; Little, 2009).

The literature provides data on the SSG organizational methods in relation to the players number and the field size (Martone et al., 2017; Hammami et al., 2018), the use of wildcard players (Sanchez-Sanchez et al., 2017; Sannicandro \& Cofano, 2017a; Sannicandro \& Cofano, 2017b; Sannicandro \& Cofano, 2018; Sannicandro et al., 2020), the recovery times and the recovery mode (Sanchez-Sanchez et al., 2017; Sparkes et al., 2018; Sarmento et al., 2018), but the filed size configuration represents a relevant variable especially for the soccer player who is confronted with situations that are cognitive challenge (Cronin et al., 2017; Tan et al., 2012; Folgado et al., 2018; Coutinho et al., 2018a; Sannicandro, 2019).

Different spatial configurations combined with modified rules create a variability environment that activate problem solving processes during high intensity exercise. But this variability consequently determines different tactical behaviours and different motor loads (Olthof et al., 2015; Sanchez et al., 2018; Joo et al., 2016; Gonçalves et al., 2016).

From the literature it emerges that the SSGs' organization on different spaces or spaces that vary during the same exercise, imposes a different motor load and very different tactical behaviours (Sanchez-Sanchez et al., 2019; Coutinho et al., 2018b; Sannicandro, 2019; Ceruso et al., 2019c).

Some studies have been developed to better understand how spatial constraints, such as field dimensions and spatial references, can influence athletic performance, but these studies have been limited to elite male soccer players (Raiola et al., 2020; Sarmento et al., 2018; Gonçalves et al., 2016; Olthof et al., 2015; Clemente et al., 2014; Gaudino et al., 2014).

The effects deriving from the use of these SSG executive variants is highly dependent on the players' technical level (Leser et al., 2019; Gaudino et al., 2014; Lacome et al., 2018; Sannicandro \& Cofano, 2018; Olthof et al., 2015). 
An open problem remains the understanding the effects on metabolic demands and exercise intensity of SSG in female soccer training.

It remains to understand if the spatial dimensions, the athletes' density, or the field configuration can determine a variation of intensity in women's football, as well as occurs in men's football, elite and youth (Sarmento et al., 2018; Travassos et al., 2018; Gonçalves et al., 2016; Olthof et al., 2015; Clemente et al., 2014; Sannicandro, 2019).

This aspect, therefore, will help coaches to design SSGs and training with greater accuracy, as both the players' number and pitch size seem to influence the high-intensity demand of one task.

The aim of this paper is to provide a narrative review based on field size effects on intensity training or metabolic demands in female soccer players.

\section{MATERIAL AND METHODS}

Using the PRISMA model (Moher et al., 2009), a systematic review of the literature was performed to analyse the relationship between the SSGs' field size and intensity training in female soccer training.

For the bibliographic search PubMed and Sport Discuss databases were used selecting articles published between 01/01/2016 and 01/12/2020. Two keyword groups were identified, using synonyms and similar terms, using the operator "OR":1) "small-sided games" OR "elite female soccer players" OR "field size" 2) "small-sided games" OR "elite female football players" OR "field size". Subsequently, all the categories were combined together using the "AND" operator.

\section{RESULTS}

The initial database search produced 77 results. After removing the duplicates (3), study on injury incidence (21), amateur soccer players (3), endocrine and biomechanical aspects (20), assessment preventive issue (12) and other aspects not related to performances (15), three studies were selected, analysed, and included in the narrative review.

The studies on SSGs demonstrated that external factors, such as the number of players or touches, the length of the game, the game objectives, the field size, the players' density, and the game surface cause different physical and physiological responses, and therefore affect the duration and number of high-intensity actions or metabolic demands.

The field size seems to represent the factor that clearly affects the internal and external load parameters, such as total distance travelled and effort perception in women's football (López-Fernández et al. 2019).

The total field size (in $\mathrm{m}^{2}$ ) affects the values of peak heart rate, the average heart rate, and the percentage of individual maximum heart rate (López-Fernández et al., 2018).

In particular, the medium side game $\left(600 \mathrm{~m}^{2}, 75 \mathrm{~m}^{2}\right.$ for each player) determines higher and statistically significant values of peak heart rate, average heart rate and percentage of maximum heart rate $(p<.05)$ compared to small ad and large side games (López-Fernández et al., 2018). 
The medium side game on natural grass and the large side game on artificial turf show the greatest decreases in countermovement jump performance, technically defined as CMJ $(p<.001)$ following exercises lasting 4 minutes (López-Fernández et al., 2018).

The natural grass surface always shows higher percentage of time spent over $90-95 \%$ and over $95-100 \%$ of the maximum heart rate, in all formats, small, medium, and large (López-Fernández et al., 2018).

When measuring the external load and energy expenditure, it is observed that medium side games determine a metabolic load relative $(\mathrm{KJ} / \mathrm{Kg})$, an average metabolic power $(\mathrm{W} / \mathrm{Kg})$ and an equivalent distance $(\mathrm{m})$ higher than the small-side games (López-Fernández et al., 2017).

\section{DISCUSSION}

The purpose of this narrative review was to understand how many studies have been carried out on the SSGs field size in female soccer.

The review also aimed to identify transfers for field practice to improve the training quality of elite female soccer players.

Today, SSGs are increasingly used in training because they reproduce the technical, tactical, and even physical demands of soccer matches (Bujalance-Moreno et al., 2018; Dellal et al., 2011; Clemente et al., 2012; Köklü et al., 2015; Joo et al., 2016), whilst allowing players to increase their fitness regardless of age or gender (Hill-Haas et al., 2011; Clemente et al., 2014; Halouani et al., 2014; Halouani et al., 2017b).

The research data differentiated between small, medium, and large sided games, in relation to the average space provided for each player (Clemente et al., 2019a \& 2019b; Sarmento et al. 2018).

The male soccer research has showed that the physiological responses of players in SSGs are affected by several external factors, such as the exercise length, rest type and period, field size, goalkeeper use, touches limitation, field surface, coaches' instructions, and coaches' incitements (Baptista et al., 2019; Castellano et al., 2013; Aguiar et al., 2012; Sarmento et al., 2018; Gonçalves et al., 2016; Olthof et al., 2015; Clemente et al., 2014; Gaudino et al., 2014).

Conversely, the physiological responses of female soccer players during SSGs have only been investigated relative to the players' number (Mara et al., 2016).

The field size is considered a key factor in soccer training because the players' density conditions internal and external load (Bujalance-Moreno et al., 2018; Gonçalves et al., 2016; Coutinho et al., 2018b).

In fact, the values of heart rate mean, the percentage of individual maximum heart rate peak and heart rate peak are significantly higher $(p<.05)$ in the medium sided games rather than in the small or large side games: they respectively touch average values between $90 \%$ and $94 \%$ of the maximum heart rate, between $95 \%$ and $98 \%$ of maximum heart rate and absolute peak values between 189 and 206 bpm (López-Fernández et al., 2017; López-Fernández et al., 2018). 
These values would suggest that the most suitable format for achieving a high intensity of exercise, with female soccer players, is precisely the medium filed size: in the case observed for $4 \mathrm{vs} 4$, a size equal to $24.5 \mathrm{~m}$ x 24.5m (López-Fernández et al., 2018).

This data is consistent with the percentage decrease observed after exercise on medium side games in the explosive strength values through $\mathrm{CMJ}$ : between rest values and post-exercise values, there was a difference $(p<.001)$ between about 4 and 8\% (López-Fernández et al., 2018).

In recent years, the wide diffusion of many instruments able to quantify the activity at various run intensities such as the Global Positioning System (GPS) have provided helpful information on competition and training demands.

These instruments made it possible to better describe the metabolic effort during the SSG and confirmed that on a natural surface, it is the medium sided games that engage the players more intensely (López-Fernández et al., 2018).

The medium side games on natural surface allow peak speeds similar to those of large ones, greater distances travelled in sprints and higher number of accelerations (López-Fernández et al., 2019).

In conclusion, the field size can be used to modulate the internal and external load in SSG training with female soccer players.

In the literature, so far, only the effects of a single SSG format have been described, namely 4vs4 without goalkeepers; further research is needed to understand the effects of different SSG formats and sizes currently used in female's soccer.

The female players density, the rules' modification, the presence of wild card players and the use of other variants in the SSG requires adequate studies in female's soccer.

The load control of specific sport exercises is useful for the injury's prevention and for relevant training organization to respond to the competitions' demands (Ruiz-Esteban et al., 2020; Vescovi, 2012a and 2012b; Vescovi and Favero, 2014).

\section{REFERENCES}

Aguiar, M., Botelho, G., Lago, C., Maças, V., and Sampaio, J. (2012). A review on the effects of soccer small-sided games. Journal of human kinetics, 33, 103-113. https://doi.org/10.2478/v10078-012$\underline{0049-\mathrm{x}}$

Baptista J., Gonçalves B., Sampaio J., Castro J., Abade E., and Travassos B.,(2019), The influence of coaches' instruction on technical actions, tactical behaviour, and external workload in football SmallSided Games, Monten J Sports Sci Med, 8, 1-8. https://doi.org/10.26773/mjssm. 190305

Bujalance-Moreno P., Latorre-Román P.A., and García-Pinillos F.,(2018), A systematic review on smallsided games in football players: acute and chronic adaptations, J Sports Sci, 29, 1-29.

Casamichana D., Castellano J., and Dellal A., (2013), Influence of different training regimes on physical and physiological demands during small-sided soccer games: continuous vs. intermittent format, J Strength Cond Res, 27, 690-697. https://doi.org/10.1519/JSC.0b013e31825d99dc 
Castellano J., Casamichana D., and Dellal A., (2013), Influence of game format and number of players on heart rate responses and physical demands in small-sided soccer games, J Strength Cond Res, 27, 1295-1303. https://doi.org/10.1519/JSC.0b013e318267a5d1

Ceruso, R., Altavilla, G., and D'Elia, F. (2020)- Evaluation of the coordinative aspects attached to the foundations of the football of the young player, Sport Science, 13 (1), 90-94.

Ceruso, R., Esposito, G., and D'Elia, F. (2019a). Coordination attached to the qualitative aspects of football, Journal of Physical Education and Sport, 19, 260, 1773-1776.

Ceruso, R., Esposito, G., and D'Elia, F. (2019b). Analysis and evaluation of the qualitative aspects of the young players, Journal of Physical Education and Sport, 19, 266, 1814-1819.

Clemente F., Couceiro M., Martins F.M., and Mendes R., (2012), The usefulness of small-sided games on soccer training, J Physic Educ Sport, 12, 93-102.

Clemente, F. M., Wong, d., Martins, F. M., and Mendes, R. S. (2014). Acute effects of the number of players and scoring method on physiological, physical, and technical performance in small-sided soccer games. Research in sports medicine (Print), 22(4), 380-397. https://doi.org/10.1080/15438627.2014.951761

Clemente, F. M., Sarmento, H., Rabbani, A., Van Der Linden, C., Kargarfard, M., and Costa, I. T. (2019a). Variations of external load variables between medium- and large-sided soccer games in professional

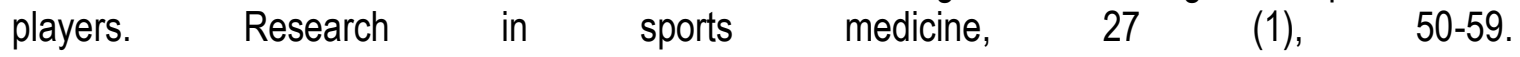
https://doi.org/10.1080/15438627.2018.1511560

Clemente, F. M., Nikolaidis, P. T., Rosemann, T., and Knechtle, B. (2019b). Shorter Small-Sided Game Sets May Increase the Intensity of Internal and External Load Measures: A Study in Amateur Soccer Players. Sports (Basel, Switzerland), 7(5), 107. https://doi.org/10.3390/sports7050107

Coutinho D., Gonçalves B., Travassos B., Abade E., Wong D.P., and Sampaio J.,(2018a), Effects of pitch spatial references on players' positioning and physical performances during football small-sided games, J Sports Sci, 11, 1-7. https://doi.org/10.1080/02640414.2018.1523671

Coutinho D., Gonçalves B., Santos S., Travassos B., Wong Del P., and Sampaio J. (2018b), Effects of the pitch configuration design on players' physical performance and movement behaviour during soccer SSG, Research in Sports Medicine, 27:3, 298-313, https://doi.org/10.1080/15438627.2018.1544133

Cronin J., Harrison C.B., Lloyd R., and Spittle M., (2017), Modifying games for improved aerobic fitness and skill acquisition in youth, Strength Cond J, 39, 82-88. https://doi.org/10.1519/SSC.0000000000000283

Dellal, A., Hill-Haas, S., Lago-Penas, C., and Chamari, K. (2011). Small-sided games in soccer: amateur vs. professional players' physiological responses, physical, and technical activities. Journal of strength and conditioning research, 25 (9), 2371-2381. https://doi.org/10.1519/JSC.0b013e3181fb4296

Di Domenico, F., D'ssanto, T., and Raiola, G. (2019). Role of speed and agility in the effectiveness of motor performance, Journal of Physical Education and Sport, 19, 271, 1836-1842.

D'Isanto, T., D'Elia, F., Raiola, G., and Altavilla, G. (2019). Assessment of sport performance: Theoretical aspects and practical indications, Sport Mont, 17, 79-82. https://doi.org/10.26773/smj.190214

Elia, F.D., Domenico, F., D'Isanto, T.D., Altavilla, G., and Raiola, G. (2020). From biomechanics to motor learning, Acta Medica Mediterranea, 36 (5), 3073-3078.

Esposito, G., and Raiola, G. (2020) Monitoring the performance and technique consolidation in youth football players, Trends in Sport Sciences, 27 (2), 93-100.

Folgado H., Bravo J., Pereira P., and Sampaio J.,(2018), Towards the use of multidimensional performance indicators in football small-sided games: the effects of pitch orientation, J Sports Sci, $14,1-8$. 
Gaudino, P., Alberti, G., and laia, F. M. (2014). Estimated metabolic and mechanical demands during different small-sided games in elite soccer players. Human movement science, 36, 123-133. https://doi.org/10.1016/j.humov.2014.05.006

Giovanni, E., Francesca, D., and Gaetano, R. (2020). A method to promote the Development of intelligence and game skills in youth football, Teoria ta Metodika Fizicnogo Vihovanna, 20 (3), 142148. https://doi.org/10.17309/tmfv.2020.3.03

Gonçalves B, Esteves P, Folgado H, et al. (2017) Effects of Pitch Area-Restrictions on Tactical Behavior, Physical, and Physiological Performances in Soccer Large-Sided Games. Journal of Strength and Conditioning Research. 31(9):2398-2408. https://doi.org/10.1519/JSC.0000000000001700

Halouani J., Chtourou H., Gabbett T., Chaouachi A., and Chamari K., (2014). Small-sided games in team sports training: a brief review, J Strength Cond Res, 28, 3594-3618. https://doi.org/10.1519/JSC.0000000000000564

Halouani J., Chtourou H., Dellal A., Chaouachi A., Chamari K.,(2017a). Soccer sm andall-sided games in young players: rule modification to induce higher physiological responses, Biol Sport, 34, 163-168. https://doi.org/10.5114/biolsport.2017.64590

Halouani J., Chtourou H., Dellal A., Chaouachi A., and Chamari K.,(2017b). The effects of game types on intensity of small-sided games among pre-adolescent youth football players, Biol Sport, 34, 157162. https://doi.org/10.5114/biolsport.2017.64589

Hammami A., Gabbet T.J., Slimani M., and Bouhlel E.,(2018). Does small-sided games improve physical fitness and team-sport-specific skills? A systematic review and meta-analysis, J Sports Med Phys Fitness, 58, 1446-1455.

Hill-Haas, S. V., Dawson, B., Impellizzeri, F. M., and Coutts, A. J. (2011). Physiology of small-sided games training in football: a systematic review. Sports medicine (Auckland, N.Z.), 41(3), 199-220. https://doi.org/10.2165/11539740-000000000-00000

Hill-Haas S.V., Dawson B.T., Coutts A.J., and Rowsell G.J., (2009a). Physiological responses and timemotion characteristics of various small-sided soccer games in youth players, J Sports Sci, 27, 1-8. https://doi.org/10.1080/02640410802206857

Hill-Haas S.V., Coutts A.J., Rowsell G.J., and Dawson B.T., (2009b). Generic versus small-sided games training in soccer, Int J Sports Med, 30, 636-642. https://doi.org/10.1055/s-0029-1220730

Idrizovic, K. (2014). Physical and anthropometric profiles of elite female soccer players. Med Sport, 67 (2), 273-87.

Joo C.H., Hwang-Bo K., Jee H.,(2016), Technical and Physical Activities of Small-Sided Games in Young Korean Soccer Players, J Strength Cond Res, 30:2164-2173. https://doi.org/10.1519/JSC.0000000000001319

Köklü, Y., Alemdaroğlu, U., Dellal, A., and Wong, D. P. (2015). Effect of different recovery durations between bouts in 3-a-side games on youth soccer players' physiological responses and technical activities. The Journal of sports medicine and physical fitness, 55(5), 430-438.

Lacome, M., Simpson, B. M., Cholley, Y., and Buchheit, M. (2018). Locomotor and heart rate responses of floaters during small-sided games in elite soccer players: Effect of pitch size and inclusion of goal keepers. Int J Sports Physiol Perform, 13, 668-671. https://doi.org/10.1123/ijspp.2017-0340

Little T., (2009). Optimizing the use of soccer drills for physiological development, Strength Cond J, 31, 67-74. https://doi.org/10.1519/SSC.0b013e3181a5910d

Leser R., Hoch T., Tan X., Moser B., Kellermayr G., Baca A., (2019), Finding efficient strategies in 3versus-2 small-sided games of youth soccer players, Kinesiology, 51, 1-9. https://doi.org/10.26582/k.51.1.7 
López-Fernández, J., Sánchez-Sánchez, J., Gallardo, L., and García-Unanue, J. (2017). Metabolic Power of Female Footballers in Various Small-Sided Games with Different Pitch Surfaces and Sizes. Sports (Basel, Switzerland), 5(2), 24. https://doi.org/10.3390/sports5020024

López-Fernández, J., Sánchez-Sánchez, J., Rodríguez-Cañamero, S., Ubago-Guisado, E., Colino, E., and Gallardo, L. (2018). Physiological responses, fatigue and perception of female soccer players in small-sided games with different pitch size and sport surfaces. Biology of sport, 35(3), 291-299. https://doi.org/10.5114/biolsport.2018.77829

López-Fernández, J., Gallardo, L., Fernández-Luna, Á., Villacañas, V., García-Unanue, J., and SánchezSánchez, J. (2019). Pitch Size and Game Surface in Different Small-Sided Games. Global Indicators, Activity Profile, and Acceleration of Female Soccer Players. Journal of strength and conditioning research, 33(3), 831-838. https://doi.org/10.1519/JSC.0000000000002090

Mara, J. K., Thompson, K. G., and Pumpa, K. L. (2016). Physical and Physiological Characteristics of Various-Sided Games in Elite Women's Soccer. International journal of sports physiology and performance, 11(7), 953-958. https://doi.org/10.1123/ijspp.2015-0087

Martone D., Giacobbe M., Capobianco A., Imperlini E., Mancini A., Capasso M., Buono P., and Orrù S.,(2017), Exercise intensity and technical demands of small-sided soccer games for under-12 and under-14 players: effect of area per player, J Strength Cond Res, 31, 1486-1492. https://doi.org/10.1519/JSC.0000000000001615

Moher, D., Liberati, A., Tetzlaff, J., and Altman, D.G. (2009). Preferred Reporting Items for Systematic Reviews and Meta-Analyses: The PRISMA Statement. PLoS Medicine, 6, e1000097. https://doi.org/10.1371/journal.pmed.1000097

Olthof SB., Frencken WG., and Lemmink KA., (2015), The older, the wider: on-field tactical behavior of elite-standard youth soccer players in small-sided games, Hum Mov Sci., 41, 92-102. https://doi.org/10.1016/j.humov.2015.02.004

Raiola, G. (2014). Motor control and learning skills according to cognitive and ecological dynamic approach in a vision on behaviorism, cognitive, Gestalt and phenomenology theories, Mediterranean Journal of Social Sciences, 15, 504-506. https://doi.org/10.5901/miss.2014.v5n15p504

Raiola, G. (2017). Motor learning and teaching method, Journal of Physical Education and Sport, 236, 2239-2243.

Raiola, G., and Altavilla, G. (2020). Testing motor skills, general and special coordinative, in young soccer. Journal of Human Sport \& Exercise, 15, Supplementary Issue, 1Proc., 206-212. https://doi.org/10.14198/ihse.2020.15.Proc2.11

Raiola, G., Esposito, G., and Sgrò, F. (2020). The formative value of soccer rules, Journal of Human Sport and Exercise, 15, S656-S663. https://doi.org/10.14198/ihse.2020.15.Proc3.18

Ruiz-Esteban, C., Olmedilla, A., Méndez, I., and Tobal, J. J. (2020). Female Soccer Players' Psychological Profile: Differences between Professional and Amateur Players. International journal of environmental research and public health, 17(12), 4357. https://doi.org/10.3390/ijerph17124357

Sampaio J., Garcia G., Maças V., Ibáñez J., Abrantes C., and Caixinha P., (2007), Heart rate and perceptual responses to $2 \times 2$ and $3 \times 3$ small-sided youth soccer games, J Sports Sci Med, 6, 121122.

Sánchez A.J., Mendo H. A., Martínez M.I., Reigal Garrido R.E., and Chirosa Ríos L.J.,(2018), Efectos de un programa de juegos reducidos sobre la toma de decisiones en chicas adolescentes, Cuadernos de Psicología del Deporte, 18, 21-30.

Sanchez-Sanchez J., Hernández D., Casamichana D., Martínez-Salazar C., Ramirez-Campillo R., and Sampaio J.,(2017), Heart Rate, Technical Performance, and Session-RPE in Elite Youth Soccer Small-Sided Games Played With Wildcard Players, J Strength Cond Res, 31, 2678-2685. https://doi.org/10.1519/JSC.0000000000001736 
Sanchez-Sanchez J. Sánchez García M., Asián-Clemente J.A., Nakamura F.Y, and Ramírez-Campillo R. (2019). Effects of the Directionality and the Order of Presentation Within the Session on the Physical Demands of Small-Sided Games in Youth Soccer, Asian J Sports Med, 10, 1-8. https://doi.org/10.5812/asjsm.87781

Sannicandro I., and Cofano G., (2018). Small-sided games activities with external wildcard soccer players, MOJ Sports Med; 2, 128-131.

Sannicandro I., and Cofano G., (2017a). Small-Sided Games in Young Soccer Players: Physical and Technical Variables, MOJ Sports Med, 1, 1-4. https://doi.org/10.15406/mojsm.2017.01.00001

Sannicandro I., and Cofano G.,(2017b) Small-Sided Games: Analysis of the Internal Load and Technical Skills in Young Soccer Players, International Journal of Science and Research (IJSR), 6, 735-739.

Sannicandro, I. (2019). Small-Sided Games configuration pitch and external motor load relationship in young soccer players: narrative literature review. Journal of Physical Education and Sport,19, (Supplement issue 5), 1989-1993.

Sannicandro I., Piccinno A., Rosa A.R., Raiola G., and Cofano G., (2020). Analysis of external load during SSG 5vs5 with and without external wildcard (jolly) soccer players. Sport Science 14, 65-71.

Sarmento H., Clemente F.M., Harper L.D., Teoldo da Costa I., Owen A., and Figueiredo A.J.,(2018). Small sided games in soccer - a systematic review, International Journal of Performance Analysis in Sport, 18, 693-749. https://doi.org/10.1080/24748668.2018.1517288

Sedano, S., Vaeyens, R., Philippaerts, R. M., Redondo, J. C., and Cuadrado, G. (2009). Anthropometric and anaerobic fitness profile of elite and non-elite female soccer players. The Journal of sports medicine and physical fitness, 49(4), 387-394.

Sparkes W., Turner A., Weston M., Russell M., Johnston M., and Kilduff L.,(2018), The neuromuscular, biochemical, endocrine and mood responses to small-sided games training in professional soccer, $\mathrm{J}$ Strength Cond Res, 32, 2569-2576. https://doi.org/10.1519/JSC.0000000000002424

Tan C.W., Chow J.Y., and Davids K., (2012). "How does TGfU work?": Examining the relationship between learning design in TGfU and a nonlinear pedagogy, Phys Educ Sport Pedagog, 17, 331 348. https://doi.org/10.1080/17408989.2011.582486

Travassos B., Coutinho D., Gonçalves B., Pedroso P., and Sampaio J.,(2018). Effects of manipulating the number of targets in U9, U11, U15 and U17 futsal players' tactical behavior, Hum Mov Sci, 61, 19-26. https://doi.org/10.1016/j.humov.2018.06.017

Vescovi J. D. (2012a). Sprint profile of professional female soccer players during competitive matches: Female Athletes in Motion (FAiM) study. Journal of sports sciences, 30(12), 1259-1265. https://doi.org/10.1080/02640414.2012.701760

Vescovi J. D. (2012b). Sprint speed characteristics of high-level American female soccer players: Female Athletes in Motion (FAiM) study. Journal of science and medicine in sport, 15(5), 474-478. https://doi.org/10.1016/j.jsams.2012.03.006

Vescovi, J. D., and Favero, T. G. (2014). Motion characteristics of women's college soccer matches: Female Athletes in Motion (FAiM) study. International journal of sports physiology and performance, 9(3), 405-414. https://doi.org/10.1123/IJSPP.2013-0526

\section{(9) $\odot \Theta \Theta$}

This work is licensed under a Attribution-NonCommercial-NoDerivatives 4.0 International (CC BY-NC-ND 4.0). 